\title{
Influence of Antisperm Antibodies in the Semen on Intracytoplasmic Sperm Injection Outcome
}

\author{
Sandro C. Esteves, Danielle T. Schneider, Sidney Verza Jr. \\ Androfert, Male Reproduction Reference Center, Campinas, Sao Paulo, Brazil
}

\begin{abstract}
Objective: The aim of this study was to analyze the influence of autoantibodies against spermatozoa present in the semen on the outcome of in vitro fertilization with intracytoplasmic sperm injection (ICSI).

Materials and Methods: We performed a retrospective analysis of clinical and laboratorial data from a six year-period ICSI cycles. Screening for the presence of ASA in the semen, by using the direct immunobeads test (IBT), was available for 351 cycles. According to the percentage of antibody-bound spermatozoa in the semen, we divided the cycles in four groups: I $(\mathrm{n}=194): 0 \%-10 \%$ ASA; II $(\mathrm{n}=107): 11 \%-20 \%$; III $(\mathrm{n}=33): 21 \%-50 \%$ and IV $(\mathrm{n}=17): 51 \%-100 \%$ ASA. Additionally, a group of 349 ICSI cycles performed with ejaculated spermatozoa from oligo/asthenozoospermic men who had insufficient number of motile sperm available for ASA screening was included for comparison. ICSI outcomes were compared among groups and included fertilization rate (2 PN), cleavage rate, cleavage velocity, embryo quality, clinical pregnancy and miscarriage rates. Data were examined statistically, with an alpha level of 5\% considered significant.

Results: Fertilization, cleavage rate and velocity, percentage of good quality embryos, as well as clinical pregnancy and miscarriage rates did not differ among different ASA levels groups. ICSI outcomes in men exhibiting different levels of autoimmunity against spermatozoa did not differ from those with severely abnormal seminal parameters.

Conclusions: Our data indicate that intracytoplasmic sperm injection (ICSI) outcomes are not influenced by ASA levels on sperm.
\end{abstract}

Key words: sperm; antibodies; in vitro fertilization; intracytoplasmic sperm injection

Int Braz J Urol. 2007; 33: 795-802

\section{INTRODUCTION}

Clinically, antibodies against sperm are found in $3 \%$ to $12 \%$ of men who undergo evaluation for infertility and can be found in the serum, seminal plasma or sperm-bound. As antibodies in the serum cannot logistically bind to sperm unless they transudate into semen, these immunoglobulins are considered clinically less important than sperm-bound antibodies. The formation of antisperm antibodies (ASA) may be a consequence of rupture in the blood-testis barrier. Overwhelming inoculations with sperm antigens or a defect in active immunosuppression may also lead to ASA formation (1). Obstruction, inflammation and trauma of the genital tract, as well as cryptorchidism, varicoceles and vasectomy have been associated with elevated levels of ASA (1).

ASA may decrease sperm motility and fertilizing capacity by either agglutination or immobilization, thus limiting sperm progression through 
the female genital tract (1). ASA may also impair sperm capacitation and acrosome reaction, thus affecting sperm-oocyte interaction (2,3). Embryo arrest at cleavage state has also been observed when autoimmunity is activated against sperm antigens $(4,5)$.

Specific tests have been developed focusing on sperm surface immunity. Immunoglobulins subclasses $\operatorname{IgA}$ and $\operatorname{IgG}$ have been demonstrated in the ejaculates of men with antisperm autoimmunity, whereas IgM seems to have no clinical impact because it is rarely detected alone or combined with $\operatorname{IgA}$ or $\operatorname{IgG}(4,5)$. From the biological standpoint, $\operatorname{Ig} \mathrm{A}$ seems to be the most important immunoglobulin, which levels at the sperm surface significantly impair sperm progression through the cervical mucus (4). Immunoglobulins can adhere regardless of their subclasses to various sperm sites (1).

Alternatives to overcome the deleterious effects of ASA, such as medication (6-8), sperm washing combined with intrauterine insemination $(6,9)$ and in vitro fertilization (10-16) have been attempted. Recent reports have shown that in vitro fertilization with intracytoplasmic sperm injection (ICSI) seems to be very promising, because it can overcome all potential ASA-related barriers (17-19). However, male immunological infertility is uncommon, and few studies on assisted reproduction techniques have been conducted on this field.

The aim of this study is to evaluate the influence of sperm surface antisperm antibodies on in vitro fertilization with intracytoplasmic sperm injection outcomes.

\section{MATERIALS AND METHODS}

We reviewed the data of 986 patients submitted to ICSI cycles, from January 2000 to November 2005. Three hundred and fifty one of them had been previously evaluated for immunological male infertility. ASA can only be assessed in ejaculates containing a minimum of 8 million motile sperm (2022). ASA screening has not been performed in the remaining 635 cycles due to technical limitations of the assay. In 286 of them, ICSI has been performed using spermatozoa retrieved from the epididymis or the testis, and the remaining 349 cycles included oligozoospermic and/or asthenozoospermic patients with insufficient number of motile sperm for ASA testing.

Screening for ASA is part of the routine semen analysis for male infertility in our institution. A low cost and reliable test for ASA determination, which utilizes poliacrilamide microspheres coated by human anti-immunoglobulin of combined IgA, IgG and IgM classes (direct immunobeads test [IBT], is used to test ejaculates for the presence of antisperm antibodies (20). Direct IBT determines the percentage of spermatozoa with surface antisperm-bound, regardless of immunoglobulin subclasses.

According to the percentage of antibody-bound spermatozoa found in the semen, we grouped the ICSI cycles as follows: group $\mathrm{I}(\mathrm{n}=194$ cycles): $0 \%-10 \%$ ASA; group II ( $n=107): 11 \%-20 \%$; group III $(n=33)$ : 21\%-50\% and group IV $(\mathrm{n}=17): 51-100 \%$. Outcomes of ICSI cycles using ejaculated spermatozoa from oligo/ asthenozoospermic men with insufficient number of motile sperm for ASA testing had been compared to the other four ASA groups. This study was approved by the institution review board.

\section{Direct Immunobeads Binding Test (IBT)}

Immunobeads $(\mathrm{H}+\mathrm{L}$, Biorad-Irvine Scientific, Santa Ana, USA) are poliacrilamide microspheres coated by human anti-immunoglobulins of combined $\operatorname{IgA}, \operatorname{IgG}$ and $\operatorname{IgM}$ classes. The beads combine to human immunoglobulins regardless of their class. Immunobeads adhere to light or heavy antibody-chains (20). The test is termed < direct> when it investigates the presence of ASA on the surface of live spermatozoa from ejaculates. Semen was obtained by masturbation after an abstinence period of 2 to 3 days. Upon liquefaction, an aliquot containing 8-10 million motile sperm was removed to test for ASA. Samples containing spermatozoa to be tested as well as the immunobeads suspension were diluted with phosphate buffer saline (PBS, Irvine Scientific, USA, $1: 2 \mathrm{v} / \mathrm{v}$ ) supplemented with $0.3 \%$ bovine albumin (Irvine Scientific, USA) and washed by centrifugation $(600 \mathrm{x}$ $\mathrm{g}$ for 20 minutes). Both sperm and immunobeads pellets were resuspended in $100 \mu \mathrm{L}$ and $50 \mu \mathrm{L}$ of PBS 
supplemented with 5\% BSA, respectively. Then, aliquots of $8 \mu \mathrm{L}$ of sperm suspension and immunobeads were mixed on a glass microscope slide. A coverglass was placed and the slides, which are prepared in duplicate, were left for incubation in a humid chamber for 8 minutes at room temperature. Finally, slides were analyzed under phase-contrast microscope at X400 magnification to check for the presence of beads bounding to the sperm surface $(20,22)$. Only motile spermatozoa were evaluated to assure viability and at least 200 cells were analyzed. Results were based on the percentage of spermatozoa with beads bounded to their membrane.

\section{Intracytoplasmic Sperm Injection (ICSI)}

Indications for ICSI in the group of men screened for ASA included teratozoospermia $(<4 \%$ normal morphology as assessed by Kruger's strict criteria), immunologic infertility ( $\geq 50 \%$ ASA as detected by direct IBT), sperm recovery of $<2.0$ million motile sperm after sperm washing for diagnostic purposes and low fertilization rates $(<30 \%)$ or multiple failures at previous conventional IVF attempts (23).

Ovarian stimulation and oocyte retrieval Ovarian hyperstimulation was achieved using GnRH analogue (nafarelin acetate) along with human menopausal gonadotrophin or highly-purified $\mathrm{hMG}$ in a long down-regulation protocol. Human chorionic gonadotrophin (hCG) was administered when at least one follicle reached $18 \mathrm{~mm}$ mean diameter on ultrasound scan. Oocytes were collected 34-36 hours after hCG administration under transvaginal ultrasound guidance.

Laboratory handling of oocytes and spermatozoa - After oocyte retrieval, the cumulusoocyte complexes were treated with 40 UI hyaluronidase for 30 seconds and incubated in $50 \mu \mathrm{L}$ droplets of culture media for one hour (IVF, Vitrolife, Sweden). Oocytes were then stripped of the remaining cumulus cells by mechanical aspiration. Ejaculated sperm samples were processed by discontinuous twolayer density gradient procedure (24).

Intracytoplasmic sperm injection (ICSI) Oocytes showing first polar body extrusion were injected with a single spermatozoon. Sperm selection and microinjection were performed using X400 magnification (25). All injections were performed at $37^{\circ} \mathrm{C}$ on an inverted microscope equipped with Hoffman modulation contrast and electrohydraulic manipulators and microinjectors.

Embryo culture - Injected oocytes were checked for fertilization on an inverted microscope 18-20 hours after ICSI, and pronuclear zygotes showing two clearly distinct pronuclei (2 PN) were considered normal fertilized and were placed into 20 $\mu \mathrm{L}$ droplets of culture media (IVF, Vitrolife, Sweden) covered with mineral oil (Ovoil, Vitrolife, Sweden). Pronuclear zygotes showing one (1 PN) or three (3 $\mathrm{PN}$ ) and more pronuclei were considered abnormally fertilized. All incubations were carried out at $37^{\circ} \mathrm{C}$ in a humidified atmosphere of $5.5 \% \mathrm{CO}_{2}$ in air. Days 2 and 3 embryos originated from 2 PN zygotes were examined and graded based on morphological features according to the criteria described by Veek (26). Grades 1 or 2 were considered good quality embryos when exhibiting 3-4 blastomeres of similar size on day 2 and 7-9 blastomeres on day 3 of embryo culture. Additionally, good quality embryos both on days 2 or 3 should not contain more than $20 \%$ cytoplasmic fragmentation. Embryos exhibiting less than 3 and 7 blastomeres on days 2 and 3, respectively, were considered as 'slow cleavage rate embryos'. On the other hand, embryos exhibiting more than 4 or 8 blastomeres on days 2 and 3, respectively, were considered as 'fast cleavage rate embryos'.

Embryo transfer - Ultrasound-guided embryo transfers were performed on day 3 using a two-step procedure (Sydney transfer set, Cook, USA). Embryos were selected for transfer based on grade and stage of development. Vaginal progesterone was given for lutheal phase support.

Pregnancy Assessment - First, serum hCG assay (> $50 \mathrm{mUI} / \mathrm{mL}$ considered positive) was performed 12 days after embryo transfer. Clinical pregnancy was confirmed by the presence of gestational sac, crown rump length and fetal heart beat at ultrasound performed 6 weeks after embryo transfer. Miscarriage was defined by the spontaneous loss of a clinical pregnancy before 20 weeks of gestation.

Laboratorial and clinical outcomes compared were fertilization (normal and abnormal), cleavage and 
cleavage velocity rates, percentage of good quality embryos on day of transfer, clinical pregnancy and miscarriage rates.

Data were examined by using non-parametric Kruskal-Wallis ANOVA and Chi-square analysis. An alpha level of 0.05 was considered significant.

\section{RESULTS}

Data are expressed as median and 25\%-75\% percentiles. Female age, number of oocytes retrieved, and number of transferred embryos were not statistically different among groups (Table-1). ASA results, sperm count and motility are also presented on Table-2. Sperm count and motility were significantly lower in the oligo/asthenozoospermic group of ICSI patients with insufficient number of motile sperm for ASA screening as compared to the other ASA groups.

Laboratory and clinical outcomes after ICSI are presented on Table-2. Normal and abnormal fertilization rates, cleavage and cleavage velocity rates, as well as the percentage of good quality embryos available for uterine transfer were not statistically different among groups. Clinical pregnancy and miscarriage rates were also not statistically different among groups (Table-2).

\section{COMMENTS}

Antisperm antibodies (ASA) can decrease the fertilizing potential by impairing sperm progression through the female genital tract and by interfering with the fertilization process. It has been shown that ASA impair sperm motility and penetration into the cervical mucus (27), and they can inhibit fertilization by binding to specific membrane antigenic structures involved in acrosome reaction and sperm-oocyte interaction $(2,3)$. Decreased fertilization and cleavage rates are expected when ASA bound sperm are used in conventional in vitro fertilization (IVF) $(14,16)$. Fertilization rates tended to decrease as the amount of antibody increased in the direct immunobead test (IBT) (12), and very low fertilization rates have been observed when $>70 \%$ of inseminated spermatozoa were coated with ASA. Once fertilization had occurred, the pregnancy rate was not affected by the severity of immunological factors (28).

Table 1 - Descriptive analysis of clinical and laboratorial data from 351 ICSI cycles subdivided into 4 groups according to the percentage of ASA on sperm as tested by direct immunobeads assay, and 349 ICSI cycles from oligo/asthenozoospermic men in which ASA testing has not been performed.

\begin{tabular}{|c|c|c|c|c|c|}
\hline & $\begin{array}{c}\text { Group I } \\
(\mathrm{n}=194) \\
\mathbf{0 - 1 0 \%} \text { ASA }\end{array}$ & $\begin{array}{c}\text { Group II } \\
(\mathrm{n}=107) \\
\mathbf{1 1 - 2 0 \%} \mathbf{A S A}\end{array}$ & $\begin{array}{c}\text { Group III } \\
(\mathrm{n}=33) \\
\mathbf{2 1 - 5 0 \%} \mathbf{A S A}\end{array}$ & $\begin{array}{c}\text { GroupIV } \\
(\mathrm{n}=17) \\
\mathbf{5 1 - 1 0 0 \%} \text { ASA }\end{array}$ & $\begin{array}{c}\text { Group V } \\
(\mathrm{n}=349) \\
\text { ASA not determined }\end{array}$ \\
\hline Female age (yrs.) & $35.0[32.0-38.0]$ & $35.0[32.0-38.0]$ & $34.0[31.0-37.0]$ & $31.0[29.0-33.0]$ & $33.0[30.0-37.0]$ \\
\hline ASA levels (\%) & $7.0[4.0-9.0]$ & $14.0[12.0-15.0]$ & $31.0[24.0-36.0]$ & $70.0[57.0-97.0]$ & Not determined \\
\hline $\begin{array}{l}\text { Number of } \\
\text { oocytes retrieved }\end{array}$ & $9.0[5.0-13.0]$ & $10.0[5.0-15.0]$ & $9.0[5.0-16.0]$ & $11.0[9.0-14.0]$ & 9.0 [5.5-14.0] \\
\hline $\begin{array}{l}\text { Number of } \\
\text { embryos } \\
\text { transferred }\end{array}$ & $3.6[3.0-4.0]$ & $3.0[2.5-4.0]$ & $4.0[3.0-4.0]$ & $4.0[2.6-4.1]$ & $4.0[2.5-4.0]$ \\
\hline
\end{tabular}

Values are median and 25\%-75\% percentiles. Kruskal-Wallis ANOVA was used for comparisons among groups. An alpha level of 0.05 was considered significant. NS= not significant. 
Table 2 - Comparative analysis of the outcomes of 351 ICSI cycles subdivided into 4 groups according to the percentage of ASA as tested by direct immunobeads assay, and 349 ICSI cycles from oligolasthenozoospermic men in which ASA testing has not been performed.

\begin{tabular}{|c|c|c|c|c|c|c|}
\hline & $\begin{array}{l}\text { Group I }(n=194) \\
\text { 0-10\% ASA }\end{array}$ & $\begin{array}{l}\text { Group II }(\mathrm{n}=107) \\
11-20 \% \text { ASA }\end{array}$ & $\begin{array}{l}\text { Group III }(\mathrm{n}=33) \\
\mathbf{2 1 - 5 0 \%} \text { ASA }\end{array}$ & $\begin{array}{l}\text { Group IV }(\mathrm{n}=17) \\
\mathbf{5 1 - 1 0 0 \%} \text { ASA }\end{array}$ & $\begin{array}{l}\text { Group V }(\mathrm{N}=349) \\
\text { ASA not determined }\end{array}$ & p Value \\
\hline $\begin{array}{l}\text { Sperm count } \\
\left(\mathrm{X} 10^{6} / \mathrm{mL}\right)\end{array}$ & $33.0[10.7-75.7]^{\mathrm{a}}$ & $44.7[9.2-65.0]^{\mathrm{b}}$ & $58.0[24.0-95.4]^{\mathrm{c}}$ & $13.3[12.9-92.0]^{\mathrm{d}}$ & $2.7[0.5-12.0]^{e}$ & a.b,c,d X e $<0.01$ \\
\hline Sperm motility (\%) & $54.0[39.5-62.0]^{\mathrm{f}}$ & $55.0[45.0-60.0]^{\mathrm{g}}$ & $52.0[32.0-66.0]^{\mathrm{h}}$ & $69.0[12.0-69.0]^{\mathrm{i}}$ & $32.0[12.0-47.0]^{\mathrm{j}}$ & $\mathrm{f}, \mathrm{gh,h,Xj}<0.01$ \\
\hline $\begin{array}{l}\text { Fertilization rate } \\
(\% 2 \mathrm{PN})\end{array}$ & $80.0[66.7-100.0]$ & $75.0[60.0-90.0]$ & $75.0[66.7-83.3]$ & $82.4[70.0-100.0]$ & $71.4[50.0-87.5]$ & NS \\
\hline $\begin{array}{l}\text { Abnormal fertilization } \\
\text { rate }(\%)\end{array}$ & $0.0[0.0-5.6]$ & $0.0[0.0-6.7]$ & $0.0[0.0-6.7]$ & $3.3[0.0-7.1]$ & $0.0[0.0-12.5]$ & NS \\
\hline Cleavage rate $(\%)$ & $100.0[100.0-100.0]$ & $100.0[100.0-100.0]$ & $100.0[94.4-100.0]$ & $100.0[100.0-100.0]$ & $100.0[92.8-100.0]$ & NS \\
\hline $\begin{array}{l}\text { Slow cleavage } \\
\text { velocity }(\%)\end{array}$ & $45.5[25.0-66.7]$ & $50.0[16.7-63.6]$ & $36.7[0.0-65.5]$ & $42.9[16.7-71.4]$ & $42.8[16.6-66.6]$ & NS \\
\hline $\begin{array}{l}\text { Fast cleavage } \\
\text { velocity }(\%)\end{array}$ & $0.0[0.0-14.3]$ & $0.0[0.0-16.7]$ & $0.0[0.0-13.9]$ & $0.0[0.0-25.0]$ & $0.0[0.0-15.4]$ & NS \\
\hline $\begin{array}{l}\text { Good quality } \\
\text { embryos (\%) }\end{array}$ & $50.0[27.3-66.7]$ & $50.0[25.0-71.4]$ & $39.2[18.3-66.7]$ & $57.1[28.6-83.3]$ & $40.0[20.0-61.5]$ & NS \\
\hline $\begin{array}{l}\text { Clinical pregnancy } \\
\text { rate }(\%)\end{array}$ & $53.5 \%$ & $52.8 \%$ & $52.0 \%$ & $50.0 \%$ & $53.5 \%$ & NS \\
\hline Miscarriage rate (\%) & $21.7 \%$ & $10.8 \%$ & $23.0 \%$ & $25.0 \%$ & $20.7 \%$ & NS \\
\hline
\end{tabular}

Values are median and $25 \%-75 \%$ percentiles. Kruskal-Wallis ANOVA was used to compare laboratory and clinical parameters among groups. Pregnancy and miscarriage rates were compared by Chi-square analysis. An alpha level of 0.05 was considered significant. NS=not significant. 
Various techniques for semen manipulation have been proposed to elute ASA bound spermatozoa and obtain ASA-free sperm pools. The success rates of these techniques in terms of effective recovery of spermatozoa not involved in antisperm antibody reaction are conflicting, with most reports showing limited success due to the great difficulty of eluting the sperm cell surface by any washing method $(29,30)$. In a previous study, we evaluated 48 men with varying levels of ASA in the semen, as determined by immunobeads binding test (IBT). We found an overall $29 \%$ decrease in the percentage of sperm-bound to autoantibodies after sperm processing by two-layer discontinuous colloidal gradient. However, the reduction in ASA levels did not occur in roughly $30 \%$ of cases, suggesting that the benefit of this approach has to be tested individually (31).

Microinjection of the compromised spermatozoa into the oocyte cytoplasm (ICSI) bypasses sperm-oocyte membrane interaction, and ICSI has been shown to increase fertilization when compared to conventional IVF in cases of male immunologic infertility. Nagy et al. (1995) analyzed the outcome of ICSI in 37 men with a proportion of antisperm antibody-bound spermatozoa of $80 \%$ or higher. ASA were determined by the mixed antiglobulin reaction (MAR) test, and the type and location of ASA were determined by the immunobead test. They concluded that fertilization, cleavage and pregnancy rates after ICSI were not influenced by the percentage of ASA-bound spermatozoa, by the dominant type of antibodies present, or by the location of ASA on the spermatozoa. However, embryo quality was lower in the ASA-positive group. In another study, similar results have been observed but a higher rate of first trimester pregnancy loss in the ASA-positive group has occurred (32). Clarke et al. (1997) and Check et al. (2000) studied 39 patients with a strong positivity on IBT $(\geq 80 \%)$ and 93 patients with various degrees of autoantibodies, respectively. They found that fertilization and pregnancy rates were comparable between different levels of ASA on sperm.

In order to re-examine data of ICSI in the light of the above mentioned reports, we analyzed ICSI outcome in 351 patients at four different levels of ASA in the semen, as determined by direct IBT. Our findings confirm that fertilization, cleavage and pregnancy rates after ICSI were not influenced by the ASA levels on sperm. However, we have not observed the negative impact on embryo quality as reported by Nagy et al. (1995) and Lahteenmaki et al. (1995), neither the increase in pregnancy loss as reported by Lahteenmaki et al. (1995) in the sperm antibody-positive patients. One possible explanation for the discrepancies in embryo quality and pregnancy loss may be the small number of cases with antisperm antibody-bound spermatozoa of $50 \%$ or higher in our study.

We also analyzed whether cleavage velocity is altered by ASA levels. Our data indicate that, irrespective of ASA levels, cleavage velocity is not affected by antisperm antibody-bound to spermatozoa.

Our findings demonstrated that fertilization, embryo development, pregnancy success and miscarriage rates after ICSI in men exhibiting varying levels of autoimmunity against spermatozoa were within the same range as our population of ICSI patients with severely abnormal seminal parameters. We speculate that ASA may become inactive within the ooplasm after microinjection, or that a segregation process may take place during the first cleavage divisions. These hypotheses seem reasonable to explain why no differences on ICSI outcome are seen in ASA patients, since inactivation and segregation also occur with the acrosome and sperm tail after microinjection (19).

\section{CONCLUSION}

Our data indicate that the presence of antisperm antibodies in the semen have no negative impact on intracytoplasmic sperm injection (ICSI) outcomes.

\section{ACKNOWLEDGMENT}

Mrs. Fabiola Bento provided editorial assistance. 


\section{REFERENCES}

1. Turek PJ: Immunopathology and infertility. In: Lipshultz LI, Howards SS (ed.), Infertility in the male. St. Louis, Mosby-Year Book Inc. 1997; pp. 305-25.

2. Srivastava PN, Sheikhnejad RG, Fayrer-Hosken R, Malter H, Brackett BG: Inhibition of fertilization of the rabbit ova in vitro by the antibody to the inner acrosomal membrane of rabbit spermatozoa. J Exp Zool. 1986; 238: 99-102.

3. Shibahara H, Burkman LJ, Isojima S, Alexander NJ: Effects of sperm-immobilizing antibodies on spermzona pellucida tight binding. Fertil Steril. 1993; 60: 5339.

4. Bates CA: Antisperm antibodies and male subfertility. Br J Urol. 1997; 80: 691-7.

5. Lombardo F, Gandini L, Lenzi A, Dondero F: Antisperm immunity in assisted reproduction. J Reprod Immunol. 2004; 62: 101-9.

6. Lahteenmaki A, Veilahti J, Hovatta O: Intra-uterine insemination versus cyclic, low-dose prednisolone in couples with male antisperm antibodies. Hum Reprod. 1995; 10: 142-7.

7. Shulman S: Therapy of immunological infertility. J Immunol Immunopharmacol. 1986; 6: 95.

8. Hendry WF, Treehuba K, Hughes L, Stedronska J, Parslow JM, Wass JA, et al.: Cyclic prednisolone therapy for male infertility associated with autoantibodies to spermatozoa. Fertil Steril. 1986; 45: 249-54.

9. Agarwal A: Treatment of immunological infertility by sperm washing and intrauterine insemination. Arch Androl. 1992; 29: 207-13.

10. Yeh WR, Acosta AA, Seltman HJ, Doncel G: Impact of immunoglobulin isotype and sperm surface location of antisperm antibodies on fertilization in vitro in the human. Fertil Steril. 1995; 63: 1287-92.

11. Acosta AA, van der Merwe JP, Doncel G, Kruger TF, Sayilgan A, Franken DR, et al.: Fertilization efficiency of morphologically abnormal spermatozoa in assisted reproduction is further impaired by antisperm antibodies on the male partner's sperm. Fertil Steril. 1994; 62: 826-33.

12. Ford WC, Williams KM, McLaughlin EA, Harrison S, Ray B, Hull MG: The indirect immunobead test for seminal antisperm antibodies and fertilization rates at in-vitro fertilization. Hum Reprod. 1996; 11: 1418-22.

13. Vazquez-Levin MH, Notrica JA, Polak de Fried E: Male immunologic infertility: sperm performance on in vitro fertilization. Fertil Steril. 1997; 68: 675-81.
14. Rajah SV, Parslow JM, Howell RJ, Hendry WF: The effects on in-vitro fertilization of autoantibodies to spermatozoa in subfertile men. Hum Reprod. 1993; 8: 1079-82.

15. Sukcharoen N, Keith J: The effect of the antisperm auto-antibody-bound sperm on in vitro fertilization outcome. Andrologia. 1995; 27: 281-9.

16. Chang TH, Jih MH, Wu TC: Relationship of sperm antibodies in women and men to human in vitro fertilization, cleavage, and pregnancy rate. Am J Reprod Immunol. 1993; 30: 108-12.

17. Nagy ZP, Verheyen G, Liu J, Joris H, Janssenswillen C, Wisanto A, et al.: Results of 55 intracytoplasmic sperm injection cycles in the treatment of male-immunological infertility. Hum Reprod. 1995; 10: 1775-80.

18. Check ML, Check JH, Katsoff D, Summers-Chase D: ICSI as an effective therapy for male factor with antisperm antibodies. Arch Androl. 2000; 45: 12530.

19. Clarke GN, Bourne H, Baker HW: Intracytoplasmic sperm injection for treating infertility associated with sperm autoimmunity. Fertil Steril. 1997; 68: 112-7.

20. BioRad: immunobead binding test (IBT) protocol for anti-sperm cell antibody detection. Bulletin 1987; 170: 1-4.

21. Mortimer D: Antisperm Antibodies: Direct Immunobead Test. In: Pratical Laboratory Andrology. New York, Oxford University Press. 1994; pp.119-21.

22. Clarke GN: Detection of antisperm antibodies using immunobeads. In: Kell BA, Webster BW (eds.), Handbook of Laboratory Diagnosis and Treatment of Infertility. Boca Raton, CRC Press. 1990; pp. 101.

23. Marinelli CM, Borges JE, Antunes Jr N: Reprodução assistida e infertilidade masculina. Int Braz J Urol. 2003; 29 (Suppl 5): 42-5.

24. Rhoden EL, Soares JB, Esteves SC: O que o laboratório pode fazer pelo espermatozóide. II Consenso Brasileiro de Infertilidade Masculina da Sociedade Brasileira de Urologia. Int Braz J Urol. 2003; 29 (Suppl 5): 50-5.

25. Esteves SC, Guidi AR, Zabaglia SFC, Verza S: Intracytoplasmic sperm injection: optical magnification during sperm selection and microinjection affects fertilization, cleavage, and pregnancy rates. Fertil Steril. 2003; 80 (3 Suppl): 124.

26. Veeck LL: Atlas of the human oocyte and early conceptus. Baltimore, Williams \& Wilkins. 1986; Vol. 2.

27. Barratt CL, Dunphy BC, McLeod I, Cooke ID: The poor prognostic value of low to moderate levels of sperm surface-bound antibodies. Hum Reprod. 1992; 7:95-8. 
28. Clarke GN: Induction of the shaking phenomenon by IgA class antispermatozoal antibodies from serum. Am J Reprod Immunol Microbiol. 1985; 9: 12-4.

29. de Almeida M, Gazagne I, Jeulin C, Herry M, BelaischAllart J, Frydman R, et al.: In-vitro processing of sperm with autoantibodies and in-vitro fertilization results. Hum Reprod. 1989; 4: 49-53.

30. Lenzi A, Gandini L, Claroni F, Lombardo F, Morrone S, Dondero F: Immunological usefulness of semen manipulation for artificial insemination homologous
(AIH) in subjects with antisperm antibodies bound to sperm surface. Andrologia. 1988; 20: 314-21.

31. Schneider DT, Feijó CM, Verza Jr S, Esteves SC: Títulos de anticorpos antiespermatozóides antes e após o processamento seminal pela técnica do gradiente descontínuo coloidal. Int Braz J Urol. 2005; 30 (Suppl): 87.

32. Lahteenmaki A, Reima I, Hovatta O: Treatment of severe male immunological infertility by intracytoplasmic sperm injection. Hum Reprod. 1995; 10: 2824-8.

Correspondence address:

Dr. Sandro Esteves

Av. Dr. Heitor Penteado, 1464

Campinas, SP, 13075-460, Brazil

Fax: + 55 193294-6992

E-mail: s.esteves@ androfert.com.br 